\title{
Research of Efficiency of Functioning of System of Electro Supply of the Enterprise by Method Multi-Criterial Analysis
}

\author{
Sadullaev NN*, Bozorov MB and Nematov SN
}

Department of Electrical Engineering, Bukhara Engineering-Tecnological Institute, Uzbekistan

\begin{abstract}
In this article, the design procedure of factor of a technical system effectiveness of electro supply of the enterprise, characterizing technical possibilities on electric power transfer is stated. The developed program can be used in power inspections of the enterprise for an estimation of system effectiveness of an electrical supply and monitoring of indicators of a power consumption of the enterprise.
\end{abstract}

Keywords: Efficiency; Integrated coefficient; Electrical Supply System; Account System; Reliability; Reservation; Power inspection; Efficiency Indicators

\section{Introduction}

One of the priority goals of power inspection of the enterprise is level of conformity of technical possibilities of system of electro supply (SES) the enterprises to modern requirements and standards on power consumption. For this purpose it is necessary to estimate quantitatively these possibilities on existing SES and to define a standard indicator for maintenance of necessary values of indicators of power consumption.

The standard indicators of efficiency SES characterizing necessary technical possibilities SES is defined on the basis of recommended project SES of the enterprise developed by experts spending energy audit of the enterprise. Use of an integrated coefficient of efficiency SES received on a basis multicriterial of the analysis allows stating the general estimation of efficiency of functioning SES of the enterprise [1].

The integrated coefficient of efficiency SES is formed under indications of systems measures and the electric power account, and also settlement data of devices SES characterizing possibility. Efficiency SES is defined basically by efficiency of transfer, quality and reliability of delivered energy, elimination of the damaged elements and abnormal operating modes SES. The interconnected coefficients integrated and receive the integrated coefficient defining level perfection SES [2-5]. For universality all coefficients calculate in relative units. At an ideal mode of power consumption all coefficients of efficiency will be equal to unit.

\section{Theoretical Part}

The integrated coefficient technical efficiency SES characterizes possibilities of devices SES on maintenance with the uninterrupted and qualitative electric power of consumers. Definition of this coefficient gives the chance to estimate how much current operating mode SES corresponds to an ideal mode of power consumption.

The coefficient technical efficiency SES is defined under the following formula:

$$
K_{\text {g.mex }}=\sum_{n=1}^{6}\left(\frac{1}{n+3} \cdot K_{n}\right)=\frac{1}{4} \cdot K_{e n}+\frac{1}{5} \cdot K_{q u}+\frac{1}{6} \cdot K_{r e l}+\frac{1}{7} \cdot K_{a c}+\frac{1}{8} \cdot K_{a u}+\frac{1}{9} \cdot K_{s . c},
$$

where the $\mathrm{K}_{\mathrm{en}}$-power coefficient characterizing efficiency of transfer of the electric power; the $\mathrm{K}_{\mathrm{qu}}$-coefficient of quality characterizing efficiency SES on maintenance of quality of the electric power; the $\mathrm{K}_{\mathrm{rel}^{-}}$ coefficient of reliability SES characterizing uninterrupted work SES; $\mathrm{K}_{\mathrm{ac}}{ }^{-}$ coefficients of the account, characterizing degrees of coverage of system of the account of the electric power; $\mathrm{K}_{\text {aut }}$ - the coefficient of automation SES characterizing level of automation SES, $\mathrm{K}_{\mathrm{s} . \mathrm{c}^{\circ}}$ - coefficient of specific cost of transfer of the electric power on SES.

These coefficients can be defined for the separate consumer, a site of workshop, workshop and as a whole on the enterprise [6]. For this purpose it is necessary to create system of gathering of initial data for chosen site SES. For definition of settlement data computer model SES of the enterprise integrated to measures and the account $[1,2]$ is used. Each effectiveness ratio is reducing their maximum (or standard) to value.

The power coefficient is defined by multiplication of power factor and a power efficiency SES:

$$
K_{e n}=K_{\eta} \cdot K_{\varphi} \text {, }
$$

Where $\mathrm{K}_{\eta}$ - the resulted efficiency SES by electric power transfer, is defined under the following formula:

$$
K_{\eta}=1-\frac{\eta_{s}-\eta_{o p}}{\eta_{s}}
$$

Where, $\eta_{\mathrm{s}}$ - standard efficiency SES of the enterprise, is established by power inspection of the enterprise for recommended project SES of the enterprise. $\eta_{\mathrm{op}}$-operating value of efficiency SES is defined on analytical data of computer model SES of the enterprise or indications of counters of systems of the account of the electric power. Computer model SES makes element wise calculation of losses of the electric power, power balance construction on all steps SES and as a whole on the enterprise [7]. On the basis of results of calculations on computer model SES efficiency SES on electric power transfer to consumers under the following formula is defined:

$$
K_{\eta}=\frac{\Sigma P_{t . c o n}}{P_{t o t}}=\frac{P_{t o t}-\Sigma \Delta P_{l . s e s}}{P_{t o t}}
$$

where $\mathrm{P}_{\text {tot }}$ - power consumption (the hour expense of the electric

*Corresponding author: Sadullaev NN, Department of Electrical Engineering, Bukhara Engineering-Tecnological Institute, Uzbekistan, Tel: 3652233086 ; E-mail: nasullo68@mail.ru

Received April 30, 2018; Accepted May 18, 2018; Published May 23, 2018

Citation: Sadullaev NN, Bozorov MB, Nematov SN (2018) Research of Efficiency of Functioning of System of Electro Supply of the Enterprise by Method MultiCriterial Analysis. J Electr Electron Syst 7: 257. doi: 10.4172/2332-0796.1000257

Copyright: ( 2018 Sadullaev NN, et al. This is an open-access article distributed under the terms of the Creative Commons Attribution License, which permits unrestricted use, distribution, and reproduction in any medium, provided the original author and source are credited. 
power) the enterprises for the counter of the electric power, $\mathrm{kW} ; \Sigma \mathrm{P}_{\mathrm{t}}$ con -total power consumption enterprise consumers, $\mathrm{kW} ; \Sigma \Delta \mathrm{P}_{1 . \mathrm{ses}}$-total power losses in elements SES by electric power transfer, $\mathrm{kW}$.

Power factor SES reduce to standard value is defined under the following formula:

$$
K_{\phi}=1-\frac{\cos \varphi_{s}-\cos \varphi_{o p}}{\cos \varphi_{s}}
$$

Where $\cos \varphi_{\mathrm{s}}$-standard value of a power coefficient of the power consumption, established by the state power inspection; $\cos \varphi_{\text {op }}$ operating value of a power coefficient of a power consumption of the enterprise, for the counter of the commercial account of the electric power.

The integrated coefficient of quality SES is defined by multiplication of following coefficients of quality of voltage SES:

$$
K_{q u}=\prod_{n=1}^{n} K_{n}=K_{1} \cdot K_{2} \cdots K_{n}=K_{\sin } \cdot K_{\Delta U} \cdot K_{s i m},
$$

Where $K_{\sin }$ - coefficient harmonistic form of voltage, $K_{\Delta U}$ - coefficient of a deviation of voltage, $K_{\text {sim }}$ - coefficient of symmetry of the voltage, defined depending on current value of voltage on tires SES.

The resulted coefficient of a deviation of voltage is defined on counter measurements under the following formula:

$$
K_{\Delta U}=1-\frac{\Delta U_{a v}}{U_{n . p h}},
$$

where $U_{a v}$ - average value of a deviation of phase voltage, is defined by nominal value of a deviation of voltage on line phases under the following formula:

$$
\Delta U_{a v}=\frac{\left|U_{p h . a}-U_{n . p h}\right|+\left|U_{p h . s}-U_{n . p h}\right|+\left|U_{p h . c}-U_{n . p h}\right|}{3},
$$

where $U_{\text {ph.a }}, U_{\text {ph.s }}, U_{\text {ph.c }}$-operating values of phase voltage under counter indications, V; $\mathrm{U}_{\mathrm{n} . \mathrm{ph}}$-nominal phase voltage, $220 \mathrm{~V}$. The resulted coefficient of symmetry is defined under the following formula:

$$
K_{\text {cus }}=1-\frac{U_{0}}{U_{H . \phi}},
$$

where the $U_{0}$-potential of a neutral line, is defined by vector addition of all phase voltage.

The coefficient harmonistic form of voltage is defined by data of analyzers of quality of the electric power during power inspections of the enterprise and defined under the following formula:

$$
K_{\text {cus }}=1-\frac{U_{H c}}{U_{H . \phi}}=1-\frac{\Sigma U_{i}}{U_{H . \phi}},
$$

where $U_{\text {нс }}$ - total operating value of no sinusoidal voltages, $V ; U_{i}$ operating value of voltage of an i-harmonic, $\mathrm{V}$.

Means of maintenance of reliability at the enterprises are: relay protection (RP), automatic input of a reserve (AIR), and also use of the radial scheme of electro supply [8,9]. To calculate coefficients of reliability SES during energy audits difficult as initial data of calculation cover the long time and demands difficult calculations. Therefore, the coefficient of reliability SES is defined indirectly, presence and technical possibilities of the devices providing uninterrupted electro supply. Optimum loading of elements SES provides the most reliable work SES. Taking into account the aforesaid the simplified coefficient of reliability SES is defined under the following formula:

$$
K_{r e l}=K_{l d . s e s} \cdot K_{r e s} \text {, }
$$

Where $\mathrm{K}_{\mathrm{Id} \text {.ses }}$ - coefficient of a deviation of optimum loading of elements SES; $K_{\text {res }}$ - the coefficient of reservation of elements SES, is defined under the following formula:

$$
K_{\text {res }}=\frac{N_{p}}{N_{\text {tot }}}=\frac{N_{r}}{N_{r}+N_{n r}},
$$

Where $\mathrm{N}_{\mathrm{r}}$-number of elements SES having possibility of reservation; the $\mathrm{N}_{\text {tot }}$-total number of elements SES of the enterprise; $\mathrm{N}_{\mathrm{nr}}$-number of elements SES which does not have possibilities of reservation $[10,11]$.

Part of the coefficients influencing reliability of electro supply is considered by other coefficients, for example, the coefficient of automation SES is considered further.

Value of optimum loading for cable lines is defined on economically effective cross-sectional area of a cable, and for transformers by economically effective loading of the transformer. The coefficient of loading reduced to optimum loading of transformers and cable lines is defined under the following formula:

$$
\begin{aligned}
& k_{\text {ld.tr }}^{\prime}=1-\left|k_{\text {ld.tr }}-k_{\text {op.tr }}\right| ; \\
& k_{\text {ld.cl }}^{\prime}=1-\left|k_{\text {ld.cl }}-k_{\text {op.cl }}\right| ;
\end{aligned}
$$

where $k_{\text {ld.tr }}$ and $k_{\text {ld.cl }}$ - operating values of coefficients of loading of transformers and cable lines, defined by the computer model SES.

The coefficient of a deviation from optimum loading for SES as a whole is defined as average value of the resulted coefficients of loading of elements SES, i.e.:

$$
K_{\text {ld.ses }}=\frac{\sum_{n=1}^{n} k_{l . n}^{\prime}}{n},
$$

Where $\mathrm{k}_{\text {ld.n }}^{\text {- }}$-coefficient of a deviation of coefficient of loading of $n$ th element SES.

The basic result of automation of a power consumption of the enterprise is regulation of parameters of the electric power: voltage and power coefficient SES level, and also automatic reservation of elements SES [11]. The automation coefficient is defined by availability of equipment automatics- $\mathrm{K}_{\mathrm{av} \text { au }}$ and in automatic regulation coefficient$\mathrm{K}_{\mathrm{reg}}$ electric power parameters under the following formula:

$$
K_{a u}=K_{a v . a u} \cdot K_{r e g},
$$

The coefficient availability of equipment SES is defined by automatics under the following formula:

$$
K_{\text {av.au }}=0,5 \cdot \frac{N_{\Delta q}}{N_{s s}}+0,3 \cdot \frac{N_{\Delta u}}{N_{s s}}+0,2 \cdot \frac{N_{\text {ars }}}{N_{s s}},
$$

Where $\mathrm{N}_{\text {ars }}$ - number of the substations having the devices of automatic transfer to reserve source; $\mathrm{N}_{\Delta \mathrm{U}}$ - number of the substations having the devices of regulation of voltage; $\mathrm{N}_{\Delta \mathrm{q}}$ - number of the substations having the devices of regulation power factor; $\mathrm{N}_{\mathrm{ps}}-$ the general number of substations at the enterprise.

The regulation coefficient is defined under the following formula:

$$
K_{r e g}=\frac{K_{-\Delta \mathrm{U}}}{\mathrm{K}_{+\Delta \phi}}=\frac{\frac{U_{s}-\Delta U_{a v}}{U_{s}}}{\frac{\cos \varphi_{s}+\Delta \cos \varphi_{r}}{\cos \varphi_{s}}},
$$

Where $\Delta \mathrm{U}_{\text {av }}$ - an average deviation of voltage on exit SES on (8), $\mathrm{V} ; \cos \varphi_{\mathrm{r}}$-real value of a power factor of a power consumption; $\Delta \cos \varphi_{\mathrm{r}}$ deviation of real value of a power factor from standard value. 
The coefficient of the account of the electric power on SES the enterprises is defined by presence of system of the account, level of automation and degree of coverage by account system distributive networks SES, and defined under the following formula:

$$
K_{a c}=K_{c . a c}+\frac{N_{\text {t.ac }}}{\mathrm{N}_{\mathrm{d} . \mathrm{p}}} \cdot K_{t . a c}
$$

Where $\mathrm{N}_{\mathrm{d} . \mathrm{p}}$-number of distributive points of the electric power to the consumer; $\mathrm{N}_{\mathrm{ac}}$-number of the distributive points having the devices of the account; $\mathrm{K}_{\text {c.ac. }}$-the coefficient characterizing presence of system of the commercial account, which at the automated system of the account (accounting software) $\mathrm{K}_{\text {cac }}=0.5$, and at not automated $\mathrm{K}_{\text {cac }}=0.25 ; \mathrm{K}_{\mathrm{tac}}$ the coefficient characterizing system of the technical account, which at the automated system of account $\mathrm{K}_{\mathrm{tac}}=0.5$, and at not automated $\mathrm{K}_{\mathrm{tac}}=0.25$.

For example, on the enterprise there is central distributive point (DP) in which it is established energy accounting software, energy is distributed on 4 transformer substations and 12 distributive points from which 8 are united in the automated system of the technical accounting of the electric energy, and also in two DP the counters which have been not included in technical accounting system and 2 DP not having counters are established. The coefficient of account SES is defined under the following formula:

$$
K_{y}=K_{\kappa, y}+\frac{N_{\text {T.y }}}{\mathrm{N}_{\mathrm{r} . \mathrm{p}}} \cdot K_{m, y}=0,5+\frac{8}{16} \cdot 0,5+\frac{2}{16} \cdot 0,25=0,5+0,312+0,031=0,844 .
$$

Economic feasibility of use of technical devices SES is defined by specific cost of transfer $1 \mathrm{kWt}$.hour energy on SES to consumers of the enterprise and defined under the following formula:

$$
K_{e f . c}=\frac{Z_{\mathrm{ee}}}{\mathrm{Z}_{\mathrm{ses}}}
$$

Where $Z_{\mathrm{ee}}$-cost of annual consumed energy of the enterprise, conventional unit; $\mathrm{Z}_{\mathrm{SES}}$-annual costs on SES, conventional unit.

This coefficient does not characterize energy efficiency manufacture, and characterizes only economic efficiency SES on electric power transfer. Energy efficiency manufactures it is characterized by the specific expense of the electric power on a unit of production, a share of power inputs in cost prices of production, etc. the General coefficient of efficiency energy department the enterprises it is defined by generalization also economic coefficients of a power consumption.

\section{Discussion}

On the basis of the developed design procedure the program on the computer for calculation of the integrated coefficient of a system effectiveness of electro supply of the industrial enterprise is made and efficiency of functioning SES in power inspections of the enterprises [3] is investigated. For reception of initial data by calculation of coefficients of efficiency SES the program «Admintools» is used. The file with data automatically remains in a document format "Excel" and the program «Efficiency SES» reads out these data and settles an invoice the integrated coefficients characterizing efficiency of modes of a power consumption of the enterprise.

Undoubtedly, offered technique has many defects and demands improvement (as the first computer or a mobile phone). Integration of a various sort of coefficients in a uniform coefficient demands some assumptions and simplifications. The full account of specific features of various coefficients at definition of the integrated coefficient will make a design procedure very difficult and bulky, hence, practically inapplicable. Authors consider, the offered method of research allows concretizing the program and bettering to spend power inspections of the enterprise. In power inspections it is necessary to use a uniform technique and a coefficient of efficiency SES of the enterprise.

\section{Conclusions}

The developed technique multicriterial the analysis of efficiency SES can be used at the decision of following problems:

- At reconstruction SES of the enterprise for comparison existing SES with recommended SES and a choice of optimum variant SES of the enterprise;

- Monitoring of coefficients of a power consumption of the enterprise for rational management энергохозяйством the enterprises;

- Carrying out internal and external energy audit the enterprises;

- Control of efficiency of functioning SES of the enterprise.

\section{References}

1. Sadullaev NN, Shoboev AH (2016) 3D-matrix model of corporate system. The Chief Power-Engineer. Moscow 9: 68-73.

2. Sadullaev NN, Shoboev AH (2017) Monitoring of the power consumption of the enterprise on the basis of a matrix model of power supply systems. Industrial Power Engineering, Moscow 4:13-16.

3. Sadullaev NN, Shoboev AH, Bozorov MB (2016) The software of the matrix model of the electricity system enterprise. The certificate of the official registration of the computer program. Intellectual property agency Republic Uzbekistan.

4. Afonso JL, Fonseca J, Martins JS, Couto CA (1997) Fuzzy Logic Technique Applied to the Control of a Three-Phase Induction Motor. Proceedings of the UK Mechatronics Forum International Conference, Portugal. pp. 142-146.

5. Chiewchitboon P, Tipsuwanpom P, Soonthomphisaj N, Piyarat W (2003) Speed Control of Three-phase Induction Motor Online Tuning by Genetic Algorithm. Fifth International Conference on Power Electronics and Drive Systems, PEDS 1: 184-188.

6. Kumar P, Mahajan A (2009) Soft Computing Techniques for the Control of an Active Power Filter. IEEE T Power Deliver 24: 452-461.

7. Ismail KB, Abdeldjebar H, Abdelkrim B, Mazari B, Rahli M (2008) Optimal Fuzzy Self-Tuning of PI Controller Using Genetic Algorithm for Induction Motor Speed Control. Int J Auto Tech 2: 85-95.

8. Guicheng W, Min Z, Xu X, Changhong J (2006) Optimization of Controller Parameters based on the Improved Genetic Algorithms. IEEE Proceedings of the 6th World Congress on Intelligent Control and Automation, Dalian, China.

9. Radha T, Chelliah TR, Pant M, Ajit A, Grosan C (2010) Optimal gain tuning of $\mathrm{PI}$ speed controller in induction motor drives using particle swarm optimization. Logic Journal of IGPL Advance Access.

10. Joao OP, Bimal BK, Eduardo BSL (2001) A Stator-Flux-Oriented VectorControlled Induction Motor Drive with Space-Vector PWM and Flux-Vector Synthesis by Neural Networks. IEEE Transaction on Industry Applications 37 1308-1318.

11. Rajasekaran S, Vijayalakshmi PGA (2005) Neural Networks, Fuzzy Logic and Genetic Algorithm: Synthesis and Applications. Prentice Hall of India, New Delhi, fifth printing 